\title{
Whole Body Integration of Gene Expression and Morphology Using Correlative Volume EM
}

Rachel Templin ${ }^{1}$, Hernando Vergara ${ }^{2}$, Constantin Pape ${ }^{1}$, Kimberly Meechan ${ }^{1}$, Valentyna Zinchenko ${ }^{1}$, Adrian Wanner ${ }^{3}$, Benjamin Titze ${ }^{4}$, Christel Genoud ${ }^{4}$, Paola Betucci ${ }^{1}$, Emily Savage ${ }^{1}$, Pedro Machado ${ }^{5}$, Oleg Simakov ${ }^{6}$, Rainer Friedrich ${ }^{4}$, Yannick Schwab ${ }^{1}$, Anna Kreshuk ${ }^{1}$, Christian Tischer ${ }^{1}$ and Detlev Arendt ${ }^{1}$

${ }^{1}$ EMBL, Heidelberg, Baden-Wurttemberg, Germany, ${ }^{2}$ Sainsbury Wellcome Centre for Neural Circuits and Behaviour, London, England, United Kingdom, ${ }^{3}$ Princeton University, Princeton, New Jersey, United States, ${ }^{4}$ FMI, Basel, Basel-Stadt, Switzerland, ${ }^{5}$ King's College London, London, England, United Kingdom, ${ }^{6}$ University of Vienna, Vienna, Wien, Austria

Early in the evolution of bilaterian animals cell types diversified, giving rise to a wide range of cell type families which allow for the complexity of animals. Animal bodies can be composed of hundreds of cell types, which differ in their location, morphology and physiology. These individual cellular traits result from the distinct sets of genes which are expressed in different cell type families ${ }^{1}$. Platynereis dumeriliii, an annelid worm, is a powerful model for studying the evolution of cell types due to its phylogenetic location relative to other model organisms. At 6dpf the cells of Platynereis have differentiated into a set of types comparable to other bilaterians. Additionally, Platynereis develops stereotypically ${ }^{2,3}$, opening the door for correlative multimodal exploration where multiple techniques cannot be conducted on a single individual.

Here we establish a link between gene expression and morphology for the entire body of Platynereis by combining whole animal volume electron microscopy (from serial blockface scanning electron microscopy) with whole mount in situ hybridization for over 200 genes (using the technique of profiling by signal probably mapping ${ }^{4}$ ) of Platynereis at $6 \mathrm{dpf}$. The data is integrated into an open access atlas, The 'Multimodal Platy Browser', to explore the cells of Platynereis (approximately 12000 cells). Additionally the Browser provides a platform that can be expanded to include additional data from different modalities at vary scales, including further electron microscopy sources, such as subvolumes from FIBSEM (Focused ion bean scanning electron microscopy), and x-ray tomography.

This multimodal atlas is a unique resource to unravel cell types and their gene expression and morphology profiles while also retaining information on their precise location within the full body plane. Used as a reference, it serves as a map for targeting specific sites in individuals at the same stage. Applying multimodal correlations, which incorporates x-ray tomography, we are developing new workflows to investigate individual cell or tissue types.

A case study for a single cell type investigation which benefits from correlative workflows is the photoreceptors. Platynereis possess both rhabdomeric and ciliary photoreceptor cell types ${ }^{5,6}$, which is also proposed to be the case for the common ancestor of bilaterians, Urbilateria. The larval eye of Platynereis is of particular interest as it undergoes considerable morphological changes during early development (48hpf - 6dpf). Effective targeting and correlative methods are required for clear identification of cells, based on morphology and expression of gene which code for light sensitive opsin proteins. The potential 
for an eye to shift from rhabdomeric to ciliary based photoreceptor would have significant implications for the evolution of photoreceptors.

\section{References}

${ }^{1}$ Arendt, D., Musser, J.M., Baker, C.V.H., Bergman, A., Cepko, C., Erwin, D.H., Pavlicev, M., Schlosser, G., Widder, S., Laubichler, M.D., et al. (2016). The origin and evolution of cell types. Nat. Rev. Genet. 17,744-757.

2 Tomer, R., Denes, A.S., Tessmar-Raible, K., and Arendt, D. (2010). Profiling by image registration reveals common origin of annelid mushroom bodies and vertebrate pallium. Cell 142, 800-809.

3 Asadulina, A., Panzera, A., Verasztó, C., Liebig, C., and Jékely, G. (2012). Whole-body gene expression pattern registration in Platynereis larvae. Evodevo 3, 27.

${ }^{4}$ Vergara, H.M., Bertucci, P.Y., Hantz, P., Tosches, M.A., Achim, K., Vopalensky, P., and Arendt, D. (2017). Whole-organism cellular gene-expression atlas reveals conserved cell types in the ventral nerve cord of Platynereis dumerilii. Proc Natl Acad Sci USA 114, 5878-5885.

5 Adrent, D., Tessmar, K., de Campos-Baptista, M., Dorrensteign, A., Wittbrodt, J. 2002. Development of pigment-cup eyes in the polychaete Platynereis dumerilii and evolutionary conservation of larval eyes in Bilateral. Development 129, 1143-54

6 Arendt, D., Tessmar-raible, K., Snyman, H., Dorresteijn, A.W., (2014) Ciliary photoreceptors with a vertebrate type opsin in an invertebrate brain. Science 306, 869-871 